\title{
Dietary fibre and phytate - a balancing act: results from three time points in a British Birth Cohort
}

\author{
Celia J. Prynne ${ }^{1}$, Aine McCarron ${ }^{1}$, Michael E. J. Wadsworth ${ }^{2}$ and Alison M. Stephen ${ }^{1}$ \\ ${ }^{1}$ Elsie Widdowson Laboratory, MRC Human Nutrition Research, Cambridge CB1 9NL, UK \\ ${ }^{2}$ MRC National Survey of Health and Development, University College and Royal Free Medical School, London WC1E 6BT, UK
}

(Received 9 February 2009 - Revised 23 June 2009 - Accepted 20 July 2009 - First published online 13 October 2009)

An investigation was carried out to determine whether there were significant changes in the intake of dietary fibre (NSP) and phytate of adult men and women in the UK from 1982 (aged 36 years) to 1999 (aged 53 years). The 1253 subjects studied were members of the Medical Research Council National Survey of Health and Development; a longitudinal study of a nationally representative cohort of births in 1946 . Food intake was recorded in a $5 \mathrm{~d}$ diary at age 36 years in 1982, 43 years in 1989 and 53 years in 1999. The food composition database was amended with revised values for phytate. Outcome measures were mean intakes of total NSP and phytate by year, sex and food source. There were significant changes in total NSP and phytate intake over the three time points. Intakes of NSP rose significantly between 1982 and 1999 for men and women but phytate intakes rose significantly only between 1989 and 1999. Cereal foods were the most important source of both NSP and phytate. Between 1989 and 1999 there was a significant increase in the contribution from pasta, rice and other grains. The present study shows that an increase in dietary fibre that is in accordance with dietary guidelines would almost inevitably be accompanied by a rise in phytate. The increased dietary phytate is discussed in relation to its recognised inhibition of mineral absorption and its merits with regard to protection against some cancers and other diseases of an ageing population.

Dietary fibre: NSP: Phytate: Dietary intake

It is now well recognised that dietary fibre is an essential component of the diet for optimum health and, as such, is included as a priority for the UK Department of Health's food and health action plan ${ }^{(1)}$. National dietary guidelines recommend an increase in the intake of NSP that are provided by a mixture of whole grains, vegetables and fruit. Phytate is a naturally occurring compound found in plant-derived foods, particularly in grains and legumes where it is the primary storage compound of $\mathrm{P}$ that is released on germination to support the emerging seedling ${ }^{(2)}$. Within the seed or grain the phytate is found mainly in the aleurone layer of wheat and barley, the embryo in maize and the seed coat of legumes. Thus an increase in the fibre of human diets is most often accompanied by an increase in the phytate content and the latter may have a considerable impact on the nutritional properties of foods. The major nutritional concern regarding phytate in the diet is its ability as a highly negatively charged ion to chelate and precipitate minerals such as $\mathrm{Fe}, \mathrm{Zn}, \mathrm{Ca}$ and $\mathrm{Mg}$. The formation of these insoluble metal cation-phytate complexes at physiological $\mathrm{pH}$ levels is a major cause of poor mineral availability, as these complexes are non-absorbable from the gastrointestinal tract $^{(3)}$. McCance \& Widdowson ${ }^{(4)}$ carried out the first human experiments on phytate and Fe absorption. Dietary phytate was a major concern during wartime food rationing in the UK when the extraction of wheat flour and the proportion of the diet that was plant-based were considerably increased. Similarly, the phytate content of many predominantly plant-based diets in the developing world today is of concern, as intakes of minerals may already be marginal ${ }^{(5)}$. Encouragement to eat high-fibre foods, especially wholewheat bread, may also compromise the $\mathrm{Fe}$ status of vulnerable groups, such as young women, in the developed world ${ }^{(6)}$.

In view of the close association between dietary fibre and phytate, it was of interest to discover how these two constituents of the diet have changed over a period of time during which the health benefits of dietary fibre have been widely advertised. The National Diet and Nutrition Survey (NDNS) has reported on intakes of NSP in adults ${ }^{(7)}$ but not phytate. Using the data provided by the Medical Research Council National Survey of Health and Development (NSHD; also known as the 1946 British Birth Cohort) we were able to examine trends over time for both phytate and NSP in the same sample of subjects at different time points.

\section{Methods \\ Subjects \\ The NSHD, also known as the 1946 British Birth Cohort, is a longitudinal study of health based on a social class-stratified, random sample of 5362 singleton births in England, Scotland and Wales during the first week of March 1946. Throughout}


childhood and adult life, medical, social, educational and other information has been collected on twenty-one occasions. Research nurses made home visits at ages 36, 43 and 53 years, in 1982, 1989 and 1999 respectively and left diet diaries to be completed. The population interviewed at the age of 53 years was, in most respects, still representative of the 53-year-old native-born population ${ }^{(8)}$. Of the 3035 cohort members who were contacted in 1999, there were 1263 individuals who had also provided dietary data in 1982 and 1989. Of these, there were 1253 subjects (562 men and 691 women) for whom there were diet records of at least $3 \mathrm{~d}$ collected at each time point. This subsample forms the population for the present analysis. The present study was conducted according to the guidelines laid down in the Declaration of Helsinki and all procedures involving human subjects were approved by the North Thames Multicentre Research Ethics Committee. Written informed consent was obtained from all subjects.

\section{Dietary assessment}

Details of the subjects and the dietary assessment methods have been reported previously ${ }^{(9)}$. Subjects were asked to record all food and drink consumed both at home and away in $5 \mathrm{~d}$ diaries using household measures and estimated portion sizes according to detailed guidance notes and photographs provided at the beginning of the diary. The diaries were coded using the in-house program DIDO (Diet In, Data Out; Price et al. $\left.{ }^{(10)}\right)$. The coded records were analysed using the in-house analysis program based on McCance and Widdowson's 'The Composition of Foods' ${ }^{(11-14)}$ that allows foods to be grouped as required for the purpose of identifying sources of particular nutrients. The groups described do not include the ingredients of composite foods such as meat dishes.

The original nutrient composition database contained limited information on the phytate content of foods ${ }^{(12,15)}$ and it was recognised that these foods had been analysed by outdated colorimetric methods. The food composition database was amended with replacement phytate values where appropriate, these being obtained from the data of Harland ${ }^{(16)}$, bearing in mind that these data were for US foods. These more recent values were applied to the principal sources of phytate such as breads, breakfast cereals, rice, beans and nuts. These values were determined using more up-to-date methods of HPLC analysis ${ }^{(17)}$. It was recognised that due to differences in varieties, growth environments and food processing in the USA these values may not have been entirely appropriate, especially for foods grown in the UK, but they were used in the absence of recent analytical data for British foods. Values for the phytate content of composite dishes were calculated from ingredients. Standard recipes as given in McCance and Widdowson were used where possible. Where no recipe was available, the cereal content of foods was ascertained from the starch and NSP content. The vegetable content of mixed dishes was calculated from the $\beta$-carotene and/or vitamin $\mathrm{C}$ content. The content of pulses in mixed dishes was derived by calculating the proportion of protein that was contributed from the pulses, the meat contribution being identifiable from the haem Fe content.

As the 1982 dietary data were analysed using the 4th edition of McCance and Widdowson ${ }^{(14)}$, only values for Southgate fibre were available. In order to compare with the 1989 and

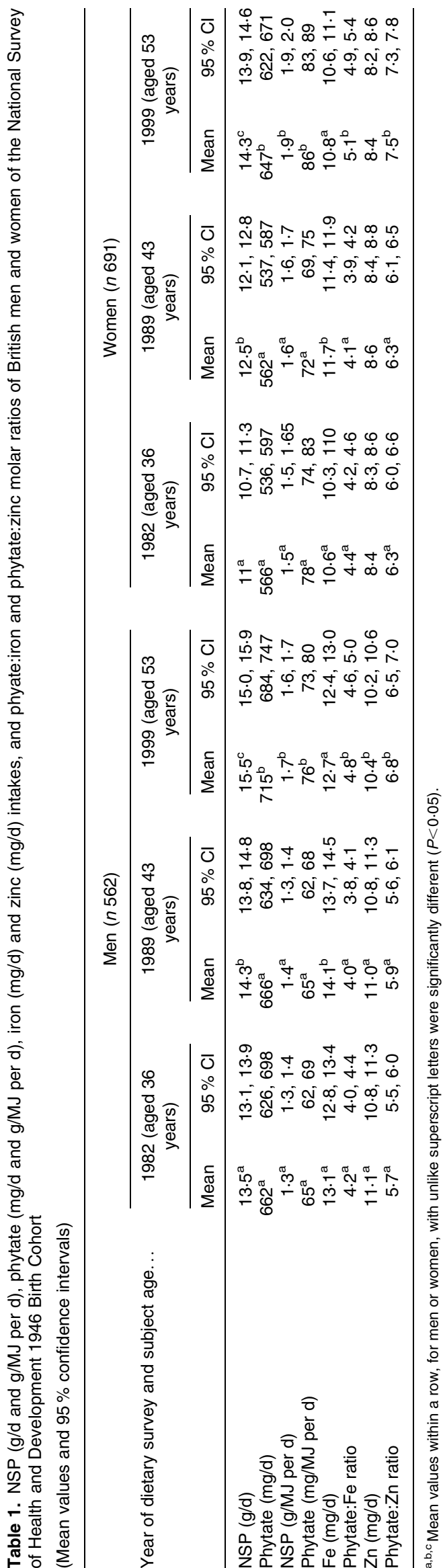


Table 2. NSP $(\mathrm{g} / \mathrm{d})$ intake of British men of the National Survey of Health and Development 1946 Birth Cohort, by year of dietary survey and by principal food sources ( $n$ 562) and percentage contribution to total from each food group

(Mean values and $95 \%$ confidence intervals and percentages of the total with their standard errors)

\begin{tabular}{|c|c|c|c|c|c|c|c|c|c|c|c|c|}
\hline \multirow{3}{*}{$\begin{array}{l}\text { Year of dietary survey } \\
\text { and subject age... } \\
\text { Food source }\end{array}$} & \multicolumn{4}{|c|}{1982 (aged 36 years) } & \multicolumn{4}{|c|}{1989 (aged 43 years) } & \multicolumn{4}{|c|}{1999 (aged 53 years) } \\
\hline & \multicolumn{2}{|c|}{$\operatorname{NSP}(g / d)$} & \multicolumn{2}{|c|}{$\begin{array}{l}\text { Percentage } \\
\text { of total }\end{array}$} & \multicolumn{2}{|c|}{$\operatorname{NSP}(g / d)$} & \multicolumn{2}{|c|}{$\begin{array}{l}\text { Percentage } \\
\text { of total }\end{array}$} & \multicolumn{2}{|c|}{ NSP $(g / d)$} & \multicolumn{2}{|c|}{$\begin{array}{l}\text { Percentage } \\
\text { of total }\end{array}$} \\
\hline & Mean & $95 \% \mathrm{Cl}$ & $\%$ & SE & Mean & $95 \% \mathrm{Cl}$ & $\%$ & SE & Mean & $95 \% \mathrm{Cl}$ & $\%$ & SE \\
\hline Rice/pasta/grains & $0.23^{a}$ & $0.18,0.28$ & $1 \cdot 6$ & 0.2 & $0.27^{a}$ & $0.20,0.34$ & $1 \cdot 7$ & 0.2 & $0.62^{b}$ & $0.53,0.71$ & 3.8 & 0.2 \\
\hline Bread & 3.39 & $3.2,3.58$ & 24.7 & 0.5 & $3 \cdot 41$ & $3.25,3.59$ & $24 \cdot 3$ & 0.5 & 3.42 & $3.25,3.59$ & $22 \cdot 4$ & 0.5 \\
\hline Breakfast cereals & $1.08^{\mathrm{a}}$ & $0.94,1.22$ & $7 \cdot 1$ & 0.4 & $1.50^{\mathrm{b}}$ & $1.32,1.68$ & 8.9 & 0.5 & $1 \cdot 27^{a, b}$ & $1.12,1.42$ & $7 \cdot 3$ & 0.4 \\
\hline Sweet cereals* & $1 \cdot 15^{\mathrm{a}}$ & $1.08,1.23$ & 8.4 & 0.3 & $1 \cdot 19^{a}$ & $1 \cdot 10,1 \cdot 28$ & 8.4 & 0.3 & $0.88^{\mathrm{b}}$ & $0.81,0.94$ & $5 \cdot 8$ & 0.2 \\
\hline Vegetables & $2 \cdot 37^{\mathrm{a}}$ & $2 \cdot 27,2.47$ & $18 \cdot 2$ & 0.4 & $2.69^{b}$ & $2 \cdot 56,2 \cdot 82$ & $19 \cdot 6$ & 0.4 & $2 \cdot 56^{\mathrm{b}}$ & $2 \cdot 42,2.67$ & $16 \cdot 6$ & 0.3 \\
\hline Pulses/nuts & 0.80 & $0.70,0.90$ & $5 \cdot 8$ & 0.3 & 0.77 & $0.70,0.85$ & 5.4 & 0.3 & 0.84 & $0.74,0.94$ & $5 \cdot 3$ & 0.3 \\
\hline Potatoes & $2 \cdot 13^{\mathrm{a}}$ & $2 \cdot 22,2 \cdot 40$ & 18.5 & 0.4 & $2 \cdot 44^{\mathrm{a}}$ & $2.33,2.55$ & $12 \cdot 8$ & 0.3 & $1.63^{\mathrm{b}}$ & $1.57,1.70$ & $16 \cdot 8$ & 0.4 \\
\hline Fruit & $1.07^{\mathrm{a}}$ & $0.97,1.16$ & 7.5 & 0.3 & $1.39^{b}$ & $1.19,1.58$ & $8 \cdot 7$ & 0.3 & $2 \cdot 04^{\mathrm{c}}$ & $1 \cdot 87,2 \cdot 2$ & 11.9 & 0.4 \\
\hline
\end{tabular}

${ }^{a, b, c}$ Mean values within a row with unlike superscript letters were significantly different $(P<0.05)$.

* 'Sweet cereals' includes cakes, biscuits and puddings.

1999 fibre intake data, values for NSP were added to the 4th edition database by extrapolating from the cereals and vegetables nutrient composition tables ${ }^{(12,15)}$.

\section{Statistical analysis}

Data analysis was by SPSS for MS Windows 10 (SPSS, Inc., Chicago, IL, USA). Mean values and $95 \%$ CI for phytate, NSP, Fe and Zn intakes, and the phytate:Fe and phytate:Zn molar ratios were calculated at each time point stratified by sex. General linear models, repeated measures, were used to identify significant changes over the 3 years, with post hoc Bonferroni comparisons.

\section{Results}

Results are from the population of 1253 individuals from whom there were dietary records of at least $3 \mathrm{~d}$ collected in 1982 at age 36 years, in 1989 at age 43 years and in 1999 at age 53 years.
Table 1 shows the mean NSP, phytate, Fe and Zn intakes and the phytate:Fe and phytate:Zn ratios of both men and women in 1982, 1989 and 1999. Phytate intakes of men and women did not change between 1982 and 1989 but rose significantly between 1989 and $1999(P<0 \cdot 005)$. NSP intakes show a clear rising trend from 1982 to 1999; all three time points were significantly different $(P<0 \cdot 05)$. Intakes of both phytate and NSP were greater in men compared with women in all 3 years but the rise between 1989 and 1999 was more marked in women. When adjusted for total energy, intakes of both phytate and NSP were significantly higher in 1999 compared with previous time points and were significantly higher in women compared with men at all three time points $(P<0 \cdot 001)$. Phytate:Fe and phytate: $\mathrm{Zn}$ ratios rose significantly between 1989 and 1999. In 1999 the phytate:Fe ratio was significantly higher in women compared with men $(P=0.024)$ and the phytate: $Z n$ ratio was significantly higher in women at all three time points $(P<0.02)$.

Tables 2-5 show the mean daily intake of NSP and phytate of men (Tables 2 and 3) and women (Tables 4 and 5) respectively from the principal sources. Also shown

Table 3. Phytate $(\mathrm{mg} / \mathrm{d})$ intake of British men of the National Survey of Health and Development 1946 Birth Cohort, by year of dietary survey and by principal food sources ( $n$ 562) and percentage contribution to total from each food group

(Mean values and $95 \%$ confidence intervals and percentages of the total with their standard errors)

\begin{tabular}{|c|c|c|c|c|c|c|c|c|c|c|c|c|}
\hline \multirow{3}{*}{$\begin{array}{l}\text { Year of dietary survey } \\
\text { and subject age... } \\
\text { Food source }\end{array}$} & \multicolumn{4}{|c|}{1982 (aged 36 years) } & \multicolumn{4}{|c|}{1989 (aged 43 years) } & \multicolumn{4}{|c|}{1999 (aged 53 years) } \\
\hline & \multicolumn{2}{|c|}{ Phytate (mg/d) } & \multicolumn{2}{|c|}{$\begin{array}{l}\text { Percentage } \\
\text { of total }\end{array}$} & \multicolumn{2}{|c|}{ Phytate (mg/d) } & \multicolumn{2}{|c|}{$\begin{array}{l}\text { Percentage } \\
\text { of total }\end{array}$} & \multicolumn{2}{|c|}{ Phytate (mg/d) } & \multicolumn{2}{|c|}{$\begin{array}{l}\text { Percentage } \\
\text { of total }\end{array}$} \\
\hline & Mean & $95 \% \mathrm{Cl}$ & $\%$ & $\mathrm{SE}$ & Mean & $95 \% \mathrm{Cl}$ & $\%$ & SE & Mean & $95 \% \mathrm{Cl}$ & $\%$ & $\mathrm{SE}$ \\
\hline Rice/pasta/grains & $31^{a}$ & 25,36 & $4 \cdot 7$ & 0.4 & $35^{\mathrm{a}}$ & 29,41 & $5 \cdot 2$ & 0.5 & $70^{b}$ & 57,84 & 8.0 & 0.51 \\
\hline Bread & 255 & 229,281 & 33.2 & 0.9 & 225 & 212,239 & 34.3 & 0.7 & 225 & 208,242 & $30 \cdot 1$ & 0.8 \\
\hline Breakfast cereals & $103^{\mathrm{a}}$ & 87,118 & $12 \cdot 1$ & 0.7 & $146^{\mathrm{b}}$ & 126,167 & $16 \cdot 4$ & 0.8 & $134^{\mathrm{b}}$ & 117,150 & $15 \cdot 1$ & 0.7 \\
\hline Sweet cereals ${ }^{\star}$ & $58^{a}$ & 53,63 & $10 \cdot 2$ & 0.4 & $35^{\mathrm{b}}$ & 31,38 & $5 \cdot 8$ & 0.3 & $38^{\mathrm{b}}$ & 34,41 & $6 \cdot 0$ & 0.3 \\
\hline Vegetables & $37^{a}$ & 35,39 & $7 \cdot 1$ & 0.2 & $46^{\mathrm{b}}$ & 42,50 & 8.0 & 0.3 & $37^{\mathrm{a}}$ & 34,40 & $5 \cdot 8$ & 0.2 \\
\hline Pulses/nuts & 43 & 38,48 & 7.4 & 0.4 & 47 & 41,52 & $7 \cdot 3$ & 0.4 & 53 & 45,61 & $7 \cdot 2$ & 0.4 \\
\hline Potatoes & $88^{a}$ & 84,91 & $18 \cdot 3$ & 0.5 & $85^{a}$ & 82,88 & $13 \cdot 8$ & 0.4 & $73^{b}$ & 68,77 & 13.6 & 0.4 \\
\hline Fruit & 1 & 1,1 & 0.7 & 0.1 & 1 & 1,1 & 0.5 & 0.1 & 2 & 1,2 & 0.3 & 0.0 \\
\hline
\end{tabular}

a,b,c Mean values within a row with unlike superscript letters were significantly different $(P<0.05)$.

* 'Sweet cereals' includes cakes, biscuits and puddings. 
Table 4. NSP $(\mathrm{g} / \mathrm{d})$ intake of British women of the National Survey of Health and Development 1946 Birth Cohort, by year of dietary survey and by principal food sources $(n 691)$ and percentage contribution to total from each food group

(Mean values and $95 \%$ confidence intervals and percentages of the total with their standard errors)

\begin{tabular}{|c|c|c|c|c|c|c|c|c|c|c|c|c|}
\hline \multirow{3}{*}{$\begin{array}{l}\text { Year of dietary survey } \\
\text { and subject age... } \\
\text { Food source }\end{array}$} & \multicolumn{4}{|c|}{1982 (aged 36 years) } & \multicolumn{4}{|c|}{1989 (aged 43 years) } & \multicolumn{4}{|c|}{1999 (aged 53 years) } \\
\hline & \multicolumn{2}{|c|}{$\operatorname{NSP}(g / d)$} & \multicolumn{2}{|c|}{$\begin{array}{l}\text { Percentage } \\
\text { of total }\end{array}$} & \multicolumn{2}{|c|}{ NSP $(g / d)$} & \multicolumn{2}{|c|}{$\begin{array}{l}\text { Percentage } \\
\text { of total }\end{array}$} & \multicolumn{2}{|c|}{$\operatorname{NSP}(g / d)$} & \multicolumn{2}{|c|}{$\begin{array}{l}\text { Percentage } \\
\text { of total }\end{array}$} \\
\hline & Mean & $95 \% \mathrm{Cl}$ & $\%$ & SE & Mean & $95 \% \mathrm{Cl}$ & $\%$ & SE & Mean & $95 \% \mathrm{Cl}$ & $\%$ & SE \\
\hline Rice/pasta/grains & $0.28^{a}$ & $0.21,0.34$ & $2 \cdot 1$ & 0.2 & $0.23^{a}$ & $0.17,0.30$ & $1 \cdot 6$ & 0.1 & $0.54^{b}$ & $0.49,0.6$ & $3 \cdot 8$ & 0.2 \\
\hline Bread & $2 \cdot 56^{a}$ & $2.42,2.69$ & 23.5 & 0.5 & $2 \cdot 64^{a, b}$ & $2.53,2.75$ & $21 \cdot 7$ & 0.4 & $2 \cdot 75^{\mathrm{b}}$ & $2 \cdot 64,2 \cdot 87$ & $19 \cdot 6$ & 0.4 \\
\hline Breakfast cereals & $1.13^{\mathrm{a}}$ & $0.98,1.27$ & 8.3 & 0.5 & $1.33^{\mathrm{b}}$ & $1.19,1.47$ & $9 \cdot 3$ & 0.4 & $1 \cdot 25^{\mathrm{a}, \mathrm{b}}$ & $1.13,1.37$ & 8.0 & 0.4 \\
\hline Sweet cereals* & $1.08^{a}$ & $1.02,1.15$ & $10 \cdot 1$ & 0.3 & $1 \cdot 13^{\mathrm{a}}$ & $1.06,1.20$ & $9 \cdot 3$ & 0.3 & $0.8^{\mathrm{b}}$ & $0.74,0.85$ & $5 \cdot 7$ & 0.2 \\
\hline Vegetables & $2.06^{\mathrm{a}}$ & $1 \cdot 9,2 \cdot 1$ & 19.9 & 0.4 & $2 \cdot 49^{\mathrm{b}}$ & $2 \cdot 4,2 \cdot 57$ & 20.9 & 0.3 & $2 \cdot 6^{\mathrm{b}}$ & $2 \cdot 5,2 \cdot 7$ & $18 \cdot 3$ & 0.3 \\
\hline Pulses/nuts & $0.48^{\mathrm{a}}$ & $0.43,0.53$ & 4.3 & 0.2 & $0.54^{a, b}$ & $0.49,0.6$ & $4 \cdot 3$ & 0.2 & $0.64^{b}$ & $0.57,0.71$ & 4.2 & 0.2 \\
\hline Potatoes & $1.41^{\mathrm{a}}$ & $1.34,1.48$ & 14.5 & 0.4 & $1.97^{\mathrm{b}}$ & $1.88,2.06$ & 11.3 & 0.3 & $1.27^{\mathrm{c}}$ & $1.22,1.32$ & $14 \cdot 8$ & 0.4 \\
\hline Fruit & $1 \cdot 26^{a}$ & $1.17,1.35$ & $10 \cdot 9$ & 0.3 & $1.62^{b}$ & $1.50,1.73$ & 11.9 & 0.3 & $2 \cdot 56^{\mathrm{c}}$ & $2 \cdot 41,2 \cdot 72$ & $16 \cdot 7$ & 0.4 \\
\hline
\end{tabular}

${ }_{a, b, c}$ Mean values within a row with unlike superscript letters were significantly different $(P<0.05)$.

* 'Sweet cereals' includes cakes, biscuits and puddings.

are the percentage contribution to total NSP and phytate from these sources. The sources shown do not add up to the total NSP and phytate, as there was also a contribution from composite dishes such as those based on meat that are not included. Bread and breakfast cereals were the main sources of both NSP and phytate at every time point but between 1989 and 1999 there was a significant increase in the quantity derived from pasta, rice and other grains in both men and women. There was no change in men's intake of NSP and phytate from bread between the three time points while that of women rose significantly between 1982 and 1999 . The contribution from breakfast cereals rose between 1982 and 1989 but fell again, although not significantly, in 1999. The contribution from sweet cereal products also fell in 1999.

NSP from vegetables, potatoes and fruit all rose between 1982 and 1989, but while NSP from fruit continued to rise in 1999, that from potatoes fell as did the phytate contribution. After combining fruit and all vegetables (including pulses but not potatoes) it was found that the increase in NSP from these foods between 1982 and 1999 was significantly greater in women than men $(P<0.001$; results not shown).

\section{Discussion}

Investigation of the diets in this cohort over a period of 17 years has shown an increased intake of NSP accompanied by an increase in the phytate content of the diet. While NSP intake increased continuously from 1982 to 1999 the increase in phytate occurred in the latter 10 years. This can be attributed to the greater consumption of fruit and vegetables (not important sources of phytate) between 1982 and 1989 that predated the greater consumption of cereal foods such as pasta, rice and wholegrain products that occurred between 1989 and 1999.

The lack of recent reports of phytate intakes in the UK may be due to the paucity of good-quality data on the phytate content of foods. As a plant component, the phytate content of foods is very variable and can depend on genotype, environmental conditions during growth and sampling procedures. Furthermore, endogenous phytases may reduce the inositol hexaphosphate content to a variable extent during storage and food processing, resulting in inositol phosphates with fewer numbers of phosphate groups that have lower metal-binding capacities ${ }^{(18)}$. Most of the data presently

Table 5. Phytate $(\mathrm{mg} / \mathrm{d})$ intakes of British women of the National Survey of Health and Development 1946 Birth Cohort, by year of dietary survey and by principal food sources $(n 691)$ and percentage contribution to total from each food group

(Mean values and $95 \%$ confidence intervals and percentages of the total with their standard errors)

\begin{tabular}{|c|c|c|c|c|c|c|c|c|c|c|c|c|}
\hline \multirow{3}{*}{$\begin{array}{l}\text { Year of dietary survey } \\
\text { and subject age... } \\
\text { Food source }\end{array}$} & \multicolumn{4}{|c|}{1982 (aged 36 years) } & \multicolumn{4}{|c|}{1989 (aged 43 years) } & \multicolumn{4}{|c|}{1999 (aged 53 years) } \\
\hline & \multicolumn{2}{|c|}{ Phytate (mg/d) } & \multicolumn{2}{|c|}{$\begin{array}{c}\text { Percentage } \\
\text { of total }\end{array}$} & \multicolumn{2}{|c|}{ Phytate (mg/d) } & \multicolumn{2}{|c|}{$\begin{array}{c}\text { Percentage } \\
\text { of total }\end{array}$} & \multicolumn{2}{|c|}{ Phytate $(\mathrm{mg} / \mathrm{d})$} & \multicolumn{2}{|c|}{$\begin{array}{l}\text { Percentage } \\
\text { of total }\end{array}$} \\
\hline & Mean & $95 \% \mathrm{Cl}$ & $\%$ & $\mathrm{SE}$ & Mean & $95 \% \mathrm{Cl}$ & $\%$ & $\mathrm{SE}$ & Mean & $95 \% \mathrm{Cl}$ & $\%$ & SE \\
\hline Rice/pasta/grains & $34^{\mathrm{a}}$ & 27,41 & $5 \cdot 2$ & 0.4 & $28^{\mathrm{a}}$ & 22,34 & $4 \cdot 8$ & 0.3 & $73^{b}$ & 61,86 & $9 \cdot 3$ & 0.54 \\
\hline Bread & $208^{a}$ & 190,226 & 34.0 & 0.9 & $181^{\mathrm{b}}$ & 171,190 & $33 \cdot 1$ & 0.7 & $191^{a, b}$ & 180,203 & 28.7 & 0.6 \\
\hline Breakfast cereals & 125 & 105,144 & $14 \cdot 7$ & 0.8 & 134 & 117,151 & 18.5 & 0.8 & 128 & 114,141 & $17 \cdot 0$ & 0.7 \\
\hline Sweet cereals* & $50^{\mathrm{a}}$ & 47,53 & $11 \cdot 7$ & 0.4 & $32^{\mathrm{b}}$ & 30,35 & 6.3 & 0.2 & $35^{\mathrm{b}}$ & 32,38 & 5.9 & 0.2 \\
\hline Vegetables & $35^{\mathrm{a}}$ & 33,36 & 8.6 & 0.3 & $43^{b}$ & 39,47 & 8.5 & 0.3 & $39^{b}$ & 36,41 & $6 \cdot 8$ & 0.2 \\
\hline Pulses/nuts & 30 & 26,34 & $6 \cdot 0$ & 0.3 & 35 & 31,39 & 6.4 & 0.3 & 46 & 39,53 & 6.5 & 0.4 \\
\hline Potatoes & $52^{\mathrm{a}}$ & 49,54 & $14 \cdot 0$ & 0.5 & $65^{\mathrm{b}}$ & 62,67 & $12 \cdot 2$ & 0.3 & $54^{\mathrm{a}}$ & 51,56 & $11 \cdot 2$ & 0.4 \\
\hline Fruit & 1 & 1,1 & 0.8 & 0.1 & 1 & 1,1 & 0.9 & 0.1 & 2 & 2,3 & 0.5 & 0.0 \\
\hline
\end{tabular}

${ }^{a, b, c}$ Mean values within a row with unlike superscript letters were significantly different $(P<0.05)$.

* 'Sweet cereals' includes cakes, biscuits and puddings. 
available in the UK are now very old, many of the analyses having been carried out before 1978 using a colorimetric method that included these partially hydrolysed inositol phosphates. It is recognised that the main limitation of the present study is that the phytate data on which the present report is based are a mixture of some of the old values and some relatively new, the latter based on HPLC analyses of foods in the USA ${ }^{(17)}$.

The other limitation of the present study may be that the members of a long-running cohort may not be representative of the general population, as those individuals who continue to contribute to the study may have particular characteristics with regard to diet and health. In addition, secular changes cannot be separated from changes due to an ageing population. The number of subjects who completed a diary in 1999 was much lower than in the preceding years and the subjects who provided data at all three time points were less representative of the general population; more than half were from non-manual occupational social classes. Despite the limitations of the cohort, the fibre intake in 1999 was very close to that of the age-matched subjects of the NDNS of adults assessed in 2000-1; 16.4 and $14 \mathrm{~g} / \mathrm{d}$ for men and women, respectively, aged $50-64$ years $^{(7)}$. This intake is still lower than the recommended average of $18 \mathrm{~g} / \mathrm{d}^{(19)}$. The proportion of NSP derived from bread consumed by men was very similar in the NSHD compared with NDNS: 22 and $21 \%$, respectively, but women in the NSHD obtained a greater proportion from bread than those in the NDNS; $24 \%$ compared with $17 \%$. As we have reported previously, bread consumption by this cohort fell from 1982 to $1999^{(9)}$, but as the NSP from bread has risen in this period it would indicate that the bread that was consumed had a higher fibre content. The consumption of breakfast cereals rose in the NSHD cohort between 1982 and $1999^{(9)}$, but the NSP from this source in 1999 was less than that reported from the NDNS. The increase in fibre intake in the NSHD cohort through the years could be in response to the frequent health messages, both in advertising and from the Health Service, concerning the health benefits of dietary fibre. The majority of the subjects in the present study, members of the 1946 cohort who have been studied at all three time points, were from non-manual occupational social classes ${ }^{(8)}$ who tend to have a greater degree of literacy and are more health-aware. The fact that older individuals are more responsive to such messages is shown by the data from the NDNS survey that show intakes of NSP rising with age ${ }^{(7)}$. Alternatively, these may be changes in dietary choices associated with ageing. The NDNS survey reported that the older group of adults (aged 50-64 years) consumed more breakfast cereals, sweet cereal products, vegetables and fruit than the 19- to 24-year age group while the latter consumed more pasta, rice and miscellaneous grains $^{(20)}$. In respect of this last food group, the NSHD cohort was not representative, increasing their intake of these foods three-fold between 1982 and $1999^{(9)}$, which may perhaps be a reflection of the bias towards non-manual social classes who are more innovative with regard to food choices. Older women, for whom the increase in the 1999 NSHD survey was proportionally greater than for men, may increase their intake of high-fibre foods, especially cereal grains, to counteract constipation and to improve gastrointestinal function.
There are many investigations into the phytate content of cereal-based diets with regard to improving mineral availability in several developing countries ${ }^{(5,21-23)}$ but few describing intakes in the UK. Data from weighed $7 \mathrm{~d}$ food records collected from seventy-six adults in Scotland in 1986 were analysed using the phytate values from McCance and Widdowson and intakes of 713 and $582 \mathrm{mg} / \mathrm{d}$ for men and women, respectively, were reported ${ }^{(24)}$. This was close to the mean reported from the present study. The NDNS survey of British adults 2000-1 did not report phytate intakes, but a secondary analysis found that the median intake of adults (aged 19-64 years) in the survey was $809 \mathrm{mg} / \mathrm{d}$, compared with the median of $616 \mathrm{mg} / \mathrm{d}$ found in the NSHD in $1999^{(25)}$. The median phytate: $\mathrm{Zn}$ ratio was also higher, 9.7 compared with 6.8 and, although not reported, the Fe:phytate ratio was also probably higher as intakes of $\mathrm{Fe}$ and $\mathrm{Zn}$ were very similar in the NDNS and the NSHD. As the intake of NSP was greatest in the older age group of the NDNS the probability is that the phytate intake was also correspondingly higher, which would make the disparity between the NSHD and NDNS phytate intakes even greater. Without knowing what data on phytate content of foods were available to those analysing the NDNS data, it is difficult to speculate on these differences.

As individuals in the UK are being encouraged to consume more high-fibre foods, especially wholegrain cereals ${ }^{(26)}$, we should be aware that this would inevitably encompass an increase in dietary phytate. Whether this is viewed as a disadvantage or a benefit would depend on the section of the population under consideration. Fe-deficiency anaemia is a problem in the UK as it is worldwide. In the UK $44 \%$ of dietary Fe is provided by cereals and cereal products and, of this, $16 \%$ is provided by wholemeal bread and high-fibre breakfast cereals. Healthy young women with initially sufficient $\mathrm{Fe}$ stores who ate high-fibre bread for 4 months had significantly reduced serum ferritin and $\mathrm{Hb}$ levels ${ }^{(6)}$. The addition of phytase to the bread in this intervention did not alleviate the effect on the $\mathrm{Fe}$ status but it has been shown in another trial that a sour-dough fermentation can increase availability of $\mathrm{Fe}$ in bread $^{(18)}$. Navert et al. showed that the length of time that bread was leavened determined the phytate content of bread and subsequently the $\mathrm{Zn}$ absorption in $\operatorname{man}^{(27)}$ but in the UK most bread is manufactured using the Chorleywood process during which the traditional $2-4 \mathrm{~h}$ fermentation is replaced by a few minutes of intense mechanical agitation ${ }^{(28)}$.

Bioavailability of non-haem $\mathrm{Fe}$ is much less than that of haem Fe and data from the NSHD cohort showed that the dietary intake of haem Fe and non-haem Fe fell between 1989 and $1999^{(29)}$. Comparison with a nationally representative sample of the same age shows that the total haem Fe intake of the 1946 cohort in 1999 was only slightly lower than that reported by the $\mathrm{NDNS}^{(7)}$. A total of $8 \%$ of women of this age (50-64 years) in the NDNS had serum ferritin concentrations below the lower limit of normal ${ }^{(30)}$. This indicates that even in women above childbearing age factors that inhibit Fe absorption are still relevant. However, factors other than phytate that influence Fe bioavailability have to be taken into account. Using the dietary data from the NSHD cohort, it was found that the Fe that is available for absorption after the enhancing or inhibiting effects of dietary factors consumed concurrently with the Fe, calculated using the algorithm of Rickard et al., 
remained fairly constant over the 17 -year period ${ }^{(31)}$. The inhibitory effect of phytate on Fe absorption in the NSHD in 1999 was overpowered by the enhancing effect of vitamin $\mathrm{C}$, the intake of which had risen dramatically over that period $^{(9)}$. However, fruit and vegetable consumption and vitamin $\mathrm{C}$ intakes were lower in the younger age groups of the NDNS, so the balance between phytate (inhibitory) and vitamin $C$ (enhancing) may not be so favourable.

So far we have considered phytate as an anti-nutritional factor, primarily with reference to Fe-deficiency anaemia, which, in the UK, is mainly a concern of premenopausal women. However, studies, reviewed by Greiner et al. (3), have shown that dietary phytate may not be an undesirable component of plant foods with respect to men and older women. Phytate may protect against some cancers ${ }^{(32-34)}$. It has been suggested that by binding metals such as $\mathrm{Cu}$ and $\mathrm{Fe}$, which could initiate oxidation reactions in the colon, phytate may protect the epithelial cells from oxidant exposure and possible mutation ${ }^{(35)}$. It has been suggested that the apparent relationship between the incidence of colon cancer and fibre intake may, in part, be due to the protective effect of the phyate that accompanies the fibre ${ }^{(36)}$. Phytate has also been shown to lower serum cholesterol and TAG in experimental animals $^{(37)}$ and to reduce the blood glucose response to a carbohydrate load $^{(38)}$. Phytate has also been found to be an inhibitor of the formation of kidney stones and, in vitro, shown to inhibit calcification in bovine pericardium ${ }^{(39,40)}$ and also to have a neuroprotective effect in a cell-culture model of Parkinson's disease ${ }^{(41)}$. In the NSHD cohort, now approaching old age, these beneficial properties of phytate may be of more significance than the negative effect on mineral balance, especially as the increased vitamin $\mathrm{C}$ has been shown to counteract the phytate inhibition ${ }^{(31)}$, and the corresponding increase in fibre intake is now well recognised to be desirable.

Our longitudinal study of dietary fibre and phytate shows that, as the intake of fibre increases, which is in accordance with dietary guidelines, phytate intakes, mainly from cereal foods, also increase. Extrapolating from this cohort to the general population it may be that higher phytate intakes will be deleterious to the availability of $\mathrm{Fe}, \mathrm{Ca}$ and $\mathrm{Zn}$ in vulnerable groups such as children and young women. On the other hand, when considering older individuals such as those in the 1946 cohort, there would appear to beneficial effects of phytate on chronic disease. When making recommendations, nutritionists should consider this balance of anti-nutritional and beneficial properties with care.

\section{Acknowledgements}

Funding for the present study was provided by the UK Medical Research Council.

C. J. P. was responsible for analysis of the data and preparation of the manuscript. A. M. reviewed the literature and contributed to the dietary analysis. M. E. J. W. was responsible for the cohort study design and data collection and provided critical approval of the manuscript. A. M. S. conceptualised the study and provided critical revision of the paper.

None of the authors had a financial or personal conflict of interest.

\section{References}

1. Department of Health (2004) Choosing Health? Choosing a better diet. A consultation on priorities for a food and health action plan. http://www.dh.gov.uk/en/Publicationsandstatistics/ Publications/PublicationsPolicyAndGuidance/DH_4082163

2. Bohn L, Meyer AS \& Rasmussen SK (2008) Phytate: impact on environment and human nutrition. A challenge for molecular breeding. J Zhejiang Univ Sci B 9, 165-191.

3. Greiner R, Konietzny U \& Jany K-D (2006) Phytate - an undesirable constituent of plant-based foods? J Ernahrungsmedizin 8, $18-28$.

4. McCance RA \& Widdowson EM (1942) Iron exchanges of adults on white and brown bread diets. Lancet i, 588-590.

5. Manary MJ, Hotz C, Krebs NF, et al. (2002) Zinc homeostasis in Malawian children consuming a high-phytate, maize-based diet. Am J Clin Nutr 75, 1057-1061.

6. Bach Kristensen M, Tetens I, Alstrup Jorgensen $\mathrm{AB}$, et al. (2005) A decrease in iron status in young healthy women after long-term daily consumption of the recommended intake of fibre-rich wheat bread. Eur J Nutr 44, 334-340.

7. Henderson L, Gregory J \& Irving K (2003) The National Diet and Nutrition Survey: Adults Aged 19 to 64 Years. Vol. 2. Energy, Protein, Carbohydrate, Fat and Alcohol Intake. London: The Stationery Office.

8. Wadsworth ME, Butterworth SL, Hardy RJ, et al. (2003) The life course prospective design: an example of benefits and problems associated with study longevity. Soc Sci Med 57, 2193-2205.

9. Prynne CJ, Paul AA, Mishra GD, et al. (2005) Changes in intake of key nutrients over 17 years during adult life of a British birth cohort. Br J Nutr 94, 368-376.

10. Price GM, Paul AA, Key FB, et al. (1995) Measurement of diet in a large national survey: comparison of computerised and manual coding in household measures. J Hum Nutr Diet 8, $417-428$.

11. Food Standards Agency (2002) McCance and Widdowson's The Composition of Foods, 6th summary ed. Cambridge, UK: Royal Society of Chemistry.

12. Holland B, Unwin I \& Buss DH (1988) Cereals and Cereal Products: Third Supplement to McCance and Widdowson's The Composition of Foods. Nottingham: Royal Society of Chemistry and Ministry of Agriculture, Fisheries and Food.

13. Holland B, Unwin ID \& Buss DH (1989) Milk and Milk Products: Fourth Supplement to McCance and Widdowson's The Composition of Foods. Cambridge, UK: Royal Society of Chemistry and Ministry of Agriculture, Fisheries and Food.

14. Paul AA \& Southgate DAT (1978) McCance and Widdowson's The Composition of Foods, 4th ed. London: H.M. Stationery Office.

15. Holland B, Unwin I \& Buss D (1991) Vegetables, Herbs and Spices: Fifth Supplement to McCance and Widdowson's The Composition of Foods. Cambridge, UK: Royal Society of Chemistry and Ministry of Agriculture, Fisheries and Food.

16. Harland B (2001) Table A.7. Phytate content of foods. In $C R C$ Handbook of Dietary Fiber in Human Nutrition, pp. 673-680 [GA Spiller, editor]. Boca Raton, FL: CRC Press.

17. Oberleas D \& Harland B (2001) Newer methods for phytate analysis. In CRC Handbook of Dietary Fiber in Human Nutrition, pp. 113-126 [GA Spiller, editor]. Boca Raton, FL: CRC Press.

18. Brune M, Rossander-Hulten L, Hallberg L, et al. (1992) Iron absorption from bread in humans: inhibiting effects of cereal fiber, phytate and inositol phosphates with different numbers of phosphate groups. J Nutr 122, 442-449.

19. Department of Health (1991) Dietary Reference Values for Food Energy and Nutrients for the United Kingdom. London: H.M. Stationery Office. 
20. Henderson L \& Gregory J (2002) The National Diet and Nutrition Survey: Adults Aged 19 to 64 Years. Vol. 1. Types and Quantities of Foods Consumed. London: The Stationery Office.

21. Kayode AP, Linnemann AR, Hounhouigan JD, et al. (2006) Genetic and environmental impact on iron, zinc, and phytate in food sorghum grown in Benin. J Agric Food Chem 54, $256-262$

22. Kim J, Paik HY, Joung H, et al. (2007) Effect of dietary phytate on zinc homeostasis in young and elderly Korean women. $J$ Am Coll Nutr 26, 1-9.

23. Hotz C \& Gibson RS (2001) Assessment of home-based processing methods to reduce the phytate content and phytate/zinc molar ratio of white maize (Zea mays). J Agric Food Chem 49, 692-698.

24. Wise A, Lockie GM \& Liddell J (1987) Dietary intakes of phytate and its meal distribution pattern amongst staff and students in an institution of higher education. Br J Nutr 58, 337-346.

25. Amirabdollahian F \& Ash R (2008) Phytate intake and molar ratio of phytate in the diet of the UK population. In TEMA 13-13th International Meeting on Trace Elements in Man and Animals, Pucón, Chile, 9-13 November 2008, pp. P012. Aberdeen, UK: TEMA.

26. Richardson D (2000) The grain, the wholegrain and nothing but the grain: the science behind wholegrains and the reduced risk of heart disease and cancer. In British Nutrition Foundation Bulletin, vol. 25, issue 4, pp. 353-360. London: British Nutrition Foundation.

27. Navert B, Sandstrom B \& Cederblad A (1985) Reduction of the phytate content of bran by leavening in bread and its effect on zinc absorption in man. Br J Nutr 53, 47-53.

28. Chamberlain N, Collins TH, Elton GA, et al. (1966) Studies on the composition of food. 2. Comparison of the nutrient content of bread made conventionally and the Chorleywood bread process. Br J Nutr 20, 747-755.

29. Johnston J, Prynne CJ, Stephen A, et al. (2007) Haem and non-haem iron intake through 17 years of adult life of a British Birth Cohort. Br J Nutr 98, 1021-1028.

30. Ruston D, Hoare J, Henderson L, et al. (2003) The National Diet and Nutrition Survey: Adults Aged 19 to 64 Years. Vol. 4.
Nutritional Status (Anthropometry and Blood Analytes), Blood Pressure and Physical Activity. London: The Stationery Office.

31. Rickard AP, Chatfield MD, Conway RE, et al. (2009) An algorithm to assess intestinal iron availability for use in dietary surveys. $\mathrm{Br} J$ Nutr (epublication ahead of print version 27 August 2009)

32. Jenab M \& Thompson L (2001) Phytic acid and cancer. In $C R C$ Handbook of Dietary Fiber in Human Nutrition, pp. 531-549 [GA Spiller, editor]. Boca Raton, FL: CRC Press.

33. Cholewa K, Parfiniewicz B, Bednarek I, et al. (2008) The influence of phytic acid on TNF- $\alpha$ and its receptors genes' expression in colon cancer Caco-2 cells. Acta Pol Pharm 65, $75-79$.

34. McFadden DW, Riggs DR, Jackson BJ, et al. (2008) Cornderived carbohydrate inositol hexaphosphate inhibits Barrett's adenocarcinoma growth by pro-apoptotic mechanisms. Oncol Rep 19, 563-566.

35. Pins J, Pereira M, Jacobs D, et al. (2001) Whole grains,cereal fiber, and chronic diseases: experimental evidence and possible biologic mechanisms. In CRC Handbook of Dietary Fiber in Human Nutrition, pp. 481-497 [GA Spiller, editor]. Boca Raton, FL: CRC Press.

36. Graf E \& Eaton JW (1993) Suppression of colonic cancer by dietary phytic acid. Nutr Cancer 19, 11-19.

37. Jariwalla RJ (1999) Inositol hexaphosphate (IP6) as an anti-neoplastic and lipid-lowering agent. Anticancer Res 19, 3699-3702.

38. Yoon JH, Thompson LU \& Jenkins DJ (1983) The effect of phytic acid on in vitro rate of starch digestibility and blood glucose response. Am J Clin Nutr 38, 835-842.

39. Grases F, Isern B, Sanchis P, et al. (2007) Phytate acts as an inhibitor in formation of renal calculi. Front Biosci 12, $2580-2587$

40. Grases F, Sanchis P, Costa-Bauza A, et al. (2008) Phytate inhibits bovine pericardium calcification in vitro. Cardiovasc Pathol 17, 139-145.

41. Xu Q, Kanthasamy AG \& Reddy MB (2008) Neuroprotective effect of the natural iron chelator, phytic acid in a cell culture model of Parkinson's disease. Toxicology 245, 101-108. 